\title{
Characterization of Personal Clothing Worn by Pesticide Sprayers in Foumbot Agricultural Area (Cameroon)
}

\author{
Sonchieu Jean ${ }^{*}{ }^{(D,}$, Bitsoga Marie Gracile1, Ngassoum Martin Benoit ${ }^{2}$ \\ ${ }^{1}$ Department of Social Economy and Family Management, Higher Technical Teacher Training College, \\ University of Bamenda, Bamenda, Cameroon \\ ${ }^{2}$ Department of Applied Chemistry, ENSAI, University of Ngaoundere, Ngaoundere, Cameroon \\ Email: ‘jsonchieu@yahoo.fr, sonchieujean@gmail.com
}

How to cite this paper: Jean, S., Gracile, B.M. and Benoit, N.M. (2019) Characterization of Personal Clothing Worn by Pesticide Sprayers in Foumbot Agricultural area (Cameroon). Agricultural Sciences, 10, 1056-1072.

https://doi.org/10.4236/as.2019.108080

Received: July 16, 2019

Accepted: August 10, 2019

Published: August 13, 2019

Copyright ( 2019 by author(s) and Scientific Research Publishing Inc. This work is licensed under the Creative Commons Attribution International License (CC BY 4.0).

http://creativecommons.org/licenses/by/4.0/

\begin{abstract}
Personal protective equipment is intended to protect worker from risks that cannot be eliminated for more effective safety. This study was aimed at evaluating the type of cloth worn by pesticide users in Foumbot agricultural area (West Region of Cameroon) and to identify signs and symptoms related to pesticides effects on human health. A survey was conducted on seventy (70) farmers randomly selected using a questionnaire made up of closed and opened questions. Specimens of cloth were collected, identified and analyzed for the water and vapor absorbency and permeability. The identification was done by burning and solubility tests. Results showed that no farmer used adequate protective clothing, they all presented many pesticide-related signs and symptoms such as dizziness, skin irritation, eye-watering and breathing difficulties; the permeation of clothes that they wear is high with high vapor and water absorbency capacity; they were made up with Cotton fiber, blended cotton fibre, wool, polyester and polyethylene; a local laminated fabric manufactured with Tri-acetate fiber was identified with great capacity of protection. This study raised inappropriate characteristics of protective materials used by farmers in Foumbot agricultural area. However, a local fabric was identified to have been adapted to pesticide applications and may be promoted after further study on the comfortability.
\end{abstract}

\section{Keywords}

Pesticides, Personal Protective Equipment, Safety, Health, Farmers

\section{Introduction}

Pesticides are a vital component and an integral part of modern agriculture 
practiced around the world. Farmers' knowledge on their use is critical to implement effective pest control and to produce safe food. Health problems related to the use of pesticides have been reported worldwide, but in developing countries, the misuse of pesticides is regularly reported mainly in areas where vegetables and industrial crops are cultivated. This poor application, generally, if prolonged, will be induced, it will induce chronic health effects such as developmental and neurobehavioral anomalies, Farmers with Chronic Kidney Disease [1] [2]. Commonly, exposure to pesticides occurs mainly through three main routes: skin, nostrils and mouth [1], Atabila et al. [1] reported that, with agricultural applicators, the dermal route is usually the most prominent exposure route.

The effects of pesticides on users will be greatly influenced by the use of personal protecting equipment (PPE). In tropical countries like Cameroon, heat does not always give chance for farmers to wear protective cloth. Sonchieu et al. [3] reported that in Santa agricultural area, the use of PPE is rare. Applicators usually dress poorly with their casual cloth and generally are not conscious of the toxicity risk from pesticides. Many were found having liver dysfunction in Foumbot area where this study was carried out [4]. As shown by Mohammad et al.; Pinheiro and Adissi [5] [6] farmers' beliefs about pesticide performance are one of the most important criteria for choosing and using pesticides. It is known that the most effective pesticides are the most toxic ones to handle with a lot of care [7]. However, the inadequate use will always lead to excess amount in food. Many factors that influence this contamination are mostly human activitydependent. The most encountered ones are pre-harvest period duration, the doses applied, and the frequency of application [6]. The time of application will mostly affect the health of the applicator that is prominently exposed to the above-cited parameters.

In Cameroon, Foumbot is known to be one of the main cropping areas in the country. Vegetables and fruits are the main crops cultivated and the National Community Driven Development Program (PNDP) [8] has brought out poor use of agricultural inputs [8]. Data indicates that high and moderate toxic pesticides are used in Foumbot. Sonchieu et al. and Tarla et al. [4] [9] reported that this involves mostly three classes of pesticides: herbicides (paraquat, diuron and glyphosate), fungicides (Ethylene-Bis-Dithiocarbamates for which the most used are maneb, zineb and macozeb), in this regard, metalaxil, which has been banned from use in Cameroon, is also frequently used; and the top applied insecticide is cypermethrin (73\%) sold in various formulations alongside deltamethrin, lamda-cyalothrin. A survey conducted in the said area revealed that applicators are poorly dressed and were presenting some signs and symptoms related to pesticides effects. Many other factors were also observed which can contribute to increase the risk of exposure among applicators though they depend on their ability to safely use the agrochemicals. Some of these factors are well known: level of education, technical assistance, participation in training, 
experience and age [10].

Many pesticide related diseases were reported in the area by Sonchieu et al. [4] to be directly linked to the body part which is not protected by a particular PPE. These were goggle for eyes, nose and mouth mask for nostrils and mouth, boots for feet. The symptoms observed were high levels of Aspartate Amino-Transferase (AST) and Alanine Amino-Tansferase (ALT) from the liver health, affection of the skin, eye (watering) and breathing systems dysfunction [11].

When all these factors are taken into consideration, one can then question, what value of protective cloth applicators wear that might be consistent to avoid penetration of pesticides through any of the following routes: dermal, oral or respiratory. This study aimed at evaluating the quality of protective materials worn by farmers in Foumbot agricultural area in relation to the type of symptoms/signs they face. Results will be used to identify adequate personal protective equipment in local markets to be put at the disposal of pesticides applicators at affordable price.

\section{Material and Methods}

\subsection{Area of Study}

Foumbot is a sub-division situated in the Noun Division, West-Region of Cameroon. Geographically it falls between $5^{\circ} 16^{\prime}$ and $5^{\circ} 35^{\prime} \mathrm{N}$; from $10^{\circ} 30^{\prime}$ to $10^{\circ} 45^{\prime}$ E; with $1100-1300$ masl at $120 \mathrm{~m}(390 \mathrm{ft})$ elevation. It covers a total surface area of $579 \mathrm{Km}^{2}$ [7]. The annual rainfall varies between 2500 and $5000 \mathrm{~mm} \mathrm{[12]} \mathrm{and}$ two seasons are observed: a rainy season from mid-March to mid-November and a dry season which runs from mid-November to mid-March. More than half of the population lives in the rural area where farming is the most important activity. Foumbot constitutes a major tomato and other vegetables growing zone alongside Santa and Mount-Cameroon zones in Cameroon [9]. The following villages were visited for this work (the number of farmers selected is in brackets): Fosset (17), Fossang (18), Mawen (20), Koupara (15). The figures in brackets indicate the number of questionnaires administered. The number of respondents was chosen according to size of the village and the number of cropping population found in the village. Participants were then randomly selected among the farmers of the village.

\subsection{Collection of Specimen of Cloths and Data}

This study was carried out from January to May 2018 and a total of 7 cloth specimens were used to triplicate tests for fiber characterization: 06 (six) specimens were collected from farmers who deliberately offered and one was selected from the local market that sold be different from those collected from farmers. A piece of protective clothing material (trousers, T-shirt, shirt) was obtained from farmers by cutting with scissors (Figure 1). These samples were so difficult to have but are considered to be representative, because pesticide sprayers wear almost the same type of clothing materials. Data based on the use of protective clothing were collected from 


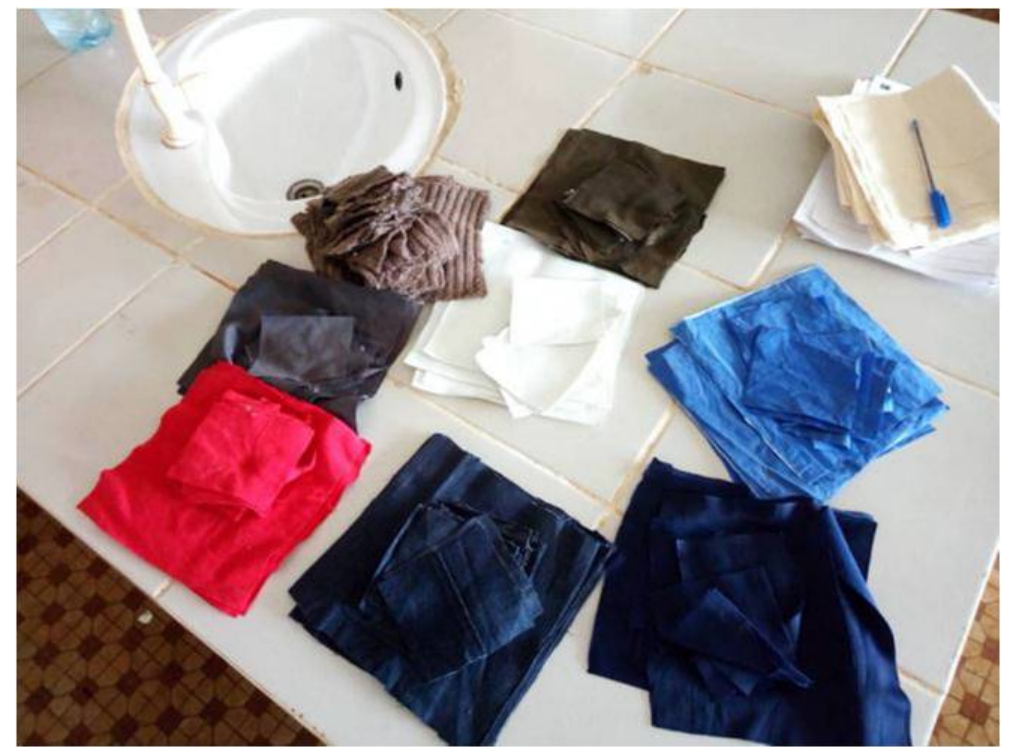

Figure 1. Specimen collected from farmers.

farmers using a questionnaire. Seventy (70) questionnaires were then administered to farmers of the four villages mentioned above. The questions focused on safety measures such as type of protective equipment used, awareness of the importance of protective clothes, care of Personal Protective Equipment (PPE) after spraying and Health problems related to the use of pesticide.

\subsection{Identification of the Protective Material Used}

Two types of tests were applied to identify the type of fiber used to manufacture the PPE worn by pesticide applicators. They were mechanical and chemical burning.

\subsubsection{Mechanical Burning Test}

Mechanical burning testing was based on cloth behavior in the flame, out of the flame at certain distance, the smell and residue which are characteristic of various fibers. Table 1 below shows the scale applied according to EN ISO 15025 [13].

\subsubsection{Solubility Test}

Five chemicals were used to detect the type of fiber used by the manufacturer to weave the fabric worn by applicators of pesticides. Table 2 presented below shows the various scales and appreciations used to identify the specimen.

\subsection{Testing of the Efficiency of the Specimen Protective Materials}

\subsubsection{Preparation of Specimen Absorbency Determination}

In order to obtain a reproducible result, the various samples were prepared and cut in order to have samples of the same size. The entire seven specimens collected from the market and farmers, were reduced to a dimension of $10 \mathrm{~cm}^{2}$ for absorption (vapor and water) and $20 \mathrm{~cm}^{2}$ for permeation. 
Table 1. Scale of fibers identification using burning test of some fibers.

\begin{tabular}{|c|c|c|c|c|c|}
\hline \multirow{2}{*}{ Type of fiber } & \multicolumn{5}{|c|}{ Characteristics of the fiber } \\
\hline & Approaching flame & In the flame & Outside the flame & Smell & Debris \\
\hline Cotton/ viscose & Do not shrink & Burn readily without melting & Continue to burn after glow & Burning paper & $\begin{array}{l}\text { Small amount of light } \\
\text { grey ash }\end{array}$ \\
\hline Wool, silk & Curl away & Burn slowly sputter & Self-extinguish & Burning hair & $\begin{array}{l}\text { Easily crushable } \\
\text { black bead }\end{array}$ \\
\hline Polyester & $\begin{array}{l}\text { Shrinks away } \\
\text { from flame }\end{array}$ & Melts, burns slowly, drips & $\begin{array}{l}\text { Burns, drips may extinguish } \\
\text { because of dripping }\end{array}$ & Sweet smell & Hard tough light color \\
\hline Asbestos & Does not shrinks & Does not burn glows & Retains shape & None & Same as original \\
\hline Nylon & $\begin{array}{l}\text { Shrinks away } \\
\text { from flame }\end{array}$ & Melts, burns slowly, drips & $\begin{array}{l}\text { Burns, drips may extinguish } \\
\text { because of dripping }\end{array}$ & Burning beans & Hard, tough tan bead \\
\hline Polyethylene & $\begin{array}{l}\text { Shrinks away } \\
\text { from flame }\end{array}$ & Melts, burns slowly, drips & Continue to burn & Burning plastic & Hard, tough tan bead \\
\hline Acrylic & $\begin{array}{l}\text { Shrinks away } \\
\text { from flame }\end{array}$ & Burns readily, sputters & Continue to burn & Acrid & Irregular, hard, black bead \\
\hline
\end{tabular}

Source: EN ISO 15025 (2017).

Table 2. Scale of fibers Identification using chemical testing.

\begin{tabular}{cccccc}
\hline Acetone acid & Sodium hypochlorite & Acetic acid & Sulfuric Acid (70\%) & Hydrochloric acid & conclusion \\
\hline Does dissolve & Swells & Does not dissolve & dissolves & Does not dissolve & Cotton fibers \\
Does not dissolve & Swells & Does not dissolve & dissolves & Does dissolve & Blended cotton fiber \\
Does dissolve & Does not dissolve & Does not dissolve & dissolves & Does dissolve & wool \\
Does not dissolve & Does not dissolve & Does not dissolves & dissolves & Dissolves & polyester \\
Does not dissolve & Does not dissolve & Dissolves & dissolves & Dissolves & Polyethylene \\
dissolves & Does not dissolve & Does not dissolve & dissolves & Dissolve & Tri-acetate \\
Does not dissolve & Does not dissolve & Dissolves & dissolves & Dissolves & Blended polyester \\
\hline
\end{tabular}

Source: Gupta and Kothari (1997). For some confused results, additional tests were performed for confirmation: Nylon 66 and Nylon 6: Soluble in formic acid (85\%) and $\mathrm{m}$-cresol; Cellulose triacetate: Soluble in chloroform and methylene dichloride; Wool: soluble in $5 \% \mathrm{NaOH}$ at room temperature; Silk: Soluble in $5 \% \mathrm{NaOH}$ (hot); Viscose rayon: dissolves in sodium zincate solution.

After weighing, using an electronic balance, they were all sent into an oven (Thermostat oven, RG-9101-1SA, EC medical USA ) and heated at $60^{\circ} \mathrm{C}$ for 15 minutes. Then they were removed and weighed in order to obtain the dry mass of the fabric (Mo).

After having the original mass of the fabric, the degree of absorption is determined by exposing or steeping each test sample in water at specific time intervals (three minutes) in order to obtain the added mass and consequently determine the rate of absorption. The formulae in determining the absorption rate of each fabric:

$$
H R=\frac{M i-M o}{M o} \times 100
$$

where: $M i=$ Final Mass; $M o=$ Initial mass or dry mass; $M i-M o=$ MA (Mass absorbed); $H R=$ Absorption Rate. 


\subsubsection{Parameters Measurement: Water Absorbency, Vapor Absorbency and Permeation}

The absorption rate of each specimen was achieved for vapor and water. For liquid (water) absorption, the various samples were dried and weighed in order to obtain the dry mass and then later were immersed into the liquid solution. These samples were removed from the liquid at different time ( 3 minutes) intervals for a total duration of 21 minutes ( 7 increments) and weighed in order to obtain the amount of water absorbed.

The vapor absorption was done by immersing all the dried samples in a vapor saturated environment after being weighed then they were removed at regular time intervals ( 3 minutes) for a duration of 21 minutes and then weighed in order to measure the amount of vapor absorbed.

\subsubsection{Permeation Test}

The various fabric samples were placed on graduated cylinders (burette) and 50 $\mathrm{ml}$ of distilled water was placed on top of each piece of fabric of $10 \mathrm{~cm}^{2}$ surface areas. The time taken by the liquid to pass through was measured in order to determine the permeability of the fabric.

\subsubsection{Selection of Appropriate Local Material}

From the local market, a series of fabric were randomly collected and tested for potential use as protective materials during pesticide spraying. One sample was selected and joined for each test carried out for specimens. The objective of this screening was to propose a locally made suitable protective cloth at cheap price.

\section{Results and Discussion}

\subsection{Characteristics of the Population}

The investigated population was made up of both female and male, the distribution of the population in the four localities, the age of respondents (farmers) and the years of experience are shown in Table 3.

The total population investigated was constituted of 70 farmers made up of females and males. But there were more females. Their age varies from less than 20 and more than 56 years old. The majority (92\%) belong to the age group 21 to 55 years old. Most of the farmers (93\%) have more than 5 years of experience in practicing cropping compared to those with less than 5 years (8\%). So, there is compatibility between the age of farmers and the number of year of experience. This longevity surely will affect their health if some precautions are not taken into consideration for the whole farming population since they have almost the same basic knowledge.

\subsection{Safety Measures Applied by Farmers}

The list of known protective accessories was provided by the Ministry of Agriculture and Rural Development (MARD) as presented in Table 4 which also states the care given to protective equipment. 
Table 3. Characteristics of the studied population.

\begin{tabular}{ccc}
\hline Factors & Characteristics & Frequency (\%) \\
\hline Sex & Male & $14(80)$ \\
& Female & $56(20)$ \\
\hline \multirow{2}{*}{ Localities } & Fossette & $17(24)$ \\
& Fossang & $18(26)$ \\
& Koupara & $15(21)$ \\
& Mawen & $20(29)$ \\
\hline Years of experience & {$[2-5]$} & $5(7)$ \\
& {$[5-10]$} & $17(24)$ \\
& {$[11 \leq]$} & $48(69)$ \\
\hline Age & {$[\leq 20]$} & $7(8)$ \\
& {$[21-35]$} & $20(29)$ \\
& {$[36-55]$} & $44(63)$ \\
& {$[56 \leq]$} & $3(4)$ \\
\hline
\end{tabular}

Table 4. Protective equipment used and other safety measures.

\begin{tabular}{|c|c|c|}
\hline Considerations & Factors & Frequency (\%) \\
\hline \multirow{16}{*}{ Protection accessories } & Hat & $62(89)$ \\
\hline & Helmet & $0(0)$ \\
\hline & Hood & $0(0)$ \\
\hline & Helmet respiratory & $21(30)$ \\
\hline & Face sheet & $0(0)$ \\
\hline & Simple Gloves & $14(20)$ \\
\hline & Chemical resistance gloves & $0(0)$ \\
\hline & Long gloves & $21(30)$ \\
\hline & Boot & $46(66)$ \\
\hline & Coat waterproof & $2(3)$ \\
\hline & Apron anti chemical & $0(0)$ \\
\hline & Pullover & $68(97)$ \\
\hline & Overall & $0(0)$ \\
\hline & Trouser & $68(97)$ \\
\hline & Dress & $6(9)$ \\
\hline & Bezel & $25(36)$ \\
\hline \multirow{4}{*}{ Time of bath after spraying } & Immediately & $47(67)$ \\
\hline & After some time & $23(33)$ \\
\hline & After the meal & $17(24)$ \\
\hline & Before the meal & $53(76)$ \\
\hline \multirow{3}{*}{ Reuse of the same clothes for following spraying } & Yes & $30(43)$ \\
\hline & No & $28(40)$ \\
\hline & Often & $12(17)$ \\
\hline
\end{tabular}


The most used protective clothing are trousers (97\%), pullover (97\%), hat (89) and boot (66\%). Contrarily, there are some which are not used at all and they include helmet, hood, face sheet, chemical resistance gloves, apron anti-chemical and overall clothing. Some PPE such as helmet respiratory, simple gloves and bezel are moderately used. After spraying, farmers immediately bath and generally before meal. However, very few respondents clean their body after some time and before meal. The reuse of the same cloth with no washing for the next spraying is equally distributed but some do not have a precise way of managing their protective cloth and can vary it or keep using the same for many spraying occasions. This will be more emphasized on the part focused on care of PPE.

\subsection{Awareness of the Importance of Protective Clothes}

Four factors were used to evaluate the awareness of farmers in term of protective materials when spraying pesticides. They include the knowledge of existence of any PPE for pesticide applicators, the knowledge of various PPE when applying pesticide, their ability to use PPE when available and the owning of any. The data obtained is shown in Table 5.

The majority of respondents are aware of the existence of PPE for pesticide sprayers and very few (6\%) do not know the meaning of PPE for somebody who uses pesticides. Among them, $63 \%$ are able to identify PPE although they do not exactly know how to use it. Only $13 \%$ cannot have an exact idea of various PPE while $79 \%$ are able to wear it if available and $21 \%$ cannot wear it even when given to them for use. With no surprise, the farmers do not have adequate PPE and declare poverty as the main obstacle for them to acquire any PPE.

\subsection{Ailments Related to the Use of Pesticides}

The symptoms and signs generally presented by pesticide users are very common. Pesticides affect various routes of entry to the body: mouth, skin, respiratory tracts, eyes and some organ such as muscles which are affected after long exposure. Table 3 indicates the overall distribution as collected from respondents.

It is shown that skin irritation, chest pain, abdominal pain and diarrhea are the top symptoms observed among more than $71 \%$ of farmers of the four villages investigated. Some are moderately observed among about $30 \%$ of the farmers and include headache, excessive sweating, watering eye, nose and mouth, muscle pain, cramp and visual disorder. The least observed symptoms are reproductive problem, fatigue and dizziness presented by $7 \%$ of farmers involved in this study.

\subsection{Care of Personal Protective Equipment (PPE) after Spraying}

Laundry is almost the only applied method to take care of cloths used by farmers who apply pesticides. This involves the laundry area, time of washing, items used and other factors (Table 6). 
Table 5. Perception of protective clothing by farmers in Foumbot agricultural area.

\begin{tabular}{|c|c|c|}
\hline Considerations & Characteristics & Frequency (\%) \\
\hline \multirow{3}{*}{ Knowledge of PPE existence } & Yes & $53(76)$ \\
\hline & No & $4(6)$ \\
\hline & Neutral & $13(19)$ \\
\hline \multirow{3}{*}{ Knowledge of PPE accessory } & Yes & $44(63)$ \\
\hline & No & $9(13)$ \\
\hline & Neutral & $17(24)$ \\
\hline \multirow{3}{*}{ Ability in putting on a given PPE } & Yes & $55(79)$ \\
\hline & No & $5(7)$ \\
\hline & Neutral & $10(14)$ \\
\hline \multirow{3}{*}{ Owning appropriate PPE } & Yes & $0(0)$ \\
\hline & No & $70(100)$ \\
\hline & Lack of money & $70(100)$ \\
\hline \multirow{12}{*}{ Symptoms and signs } & Headache & $30(42)$ \\
\hline & Fatigue & $20(29)$ \\
\hline & Dizziness & $20(29)$ \\
\hline & Abdominal pain and diarrhea & $50(71)$ \\
\hline & Excessive sweating & $21(30)$ \\
\hline & Chest pain & $51(73)$ \\
\hline & Watering eyes, nose and mouth & $33(47)$ \\
\hline & Muscle pain & $30(42)$ \\
\hline & Cramp & $31(44)$ \\
\hline & Visual Disorder & $35(50)$ \\
\hline & Skin irritation & $60(86)$ \\
\hline & Reproductive problem & $5(7)$ \\
\hline
\end{tabular}

There are two places where farmers declared that they wash their clothes after pesticide application: river and house (most applied). In most cases, clothes are washed immediately or after some days depending on the frequency of treatment or the intensity of work since some do spraying of pesticides as a job. In most cases, they use cold water, but some use warm water to wash their clothes. In both cases, they use detergent. No one uses gloves when washing their protective cloths either constantly or occasionally.

They wash these working materials separately from other family items. After washing they dry them under the sunlight and in most cases, keep them in storage room where food is generally found or dry them outside under the shade of the veranda and keep them there until next use. These clothes are generally discarded through three ways: dumping site, burning or burying. But dumping remains the most applied way (66\%). 
Table 6. Care of used spraying cloths by farmers of Foumbot.

\begin{tabular}{ccc}
\hline Considerations & Characteristics & Frequency (\%) \\
\hline Laundry place & House (in a bucket) & $44(63)$ \\
& River & $26(37)$ \\
\hline Washing time after spraying & Immediately & $41(59)$ \\
\hline Laundry items & days after & $29(41)$ \\
\hline \multirow{2}{*}{ Use of gloves during laundry } & Cold water + soap & $51(73)$ \\
& Hot water + soap & $19(27)$ \\
Mixing with other cloths & Yes & $0(0)$ \\
& No & $70(100)$ \\
\hline Storage space of PPE & Often & $70(100)$ \\
& Mixed with other family clothes & $0(0)$ \\
\hline Disposal of PPE & Bedroom & $0(0)$ \\
& Food storage & $55(79)$ \\
& Outside & $15(21)$ \\
\hline
\end{tabular}

\subsection{Type of Fibers Used for Protective Cloths by Pesticide Users}

The six (6) specimens of protective materials collected from the field are shown in Table 7. They were trousers (jeans and simple fabric), T-shirt, sweater and track suit.

After identification through the two methods, confirmation was given accordingly. Cloth worn by pesticides sprayers is made up of cotton fiber, wool, polyester, polyethylene and tri-acetate. None of them is adapted to protecting the farmer against the chemicals they apply.

\subsection{Chemical Properties of Specimen}

Many other chemical properties of specimens collected from farmers were evaluated. These include water absorption, vapor absorption and permeability.

\subsubsection{Water Absorption}

Water absorption was measured for a length of 24 minutes for all the samples as shown by Figure 2. Jeans (Figure 2(b)) which had a dry mass of $3.59 \mathrm{~g}$ ended up having a final mass of 11.6 grams upon absorption thereby leading to the conclusion that this textile is able to absorb over three times its weight. Wool sweaters (Figure 2(c)) had a dry mass of $2.53 \mathrm{~g}$ and a final mass of $22.99 \mathrm{~g}$ which is a frightening result for those who use it as protective clothing as it is able to bear up to approximately 10 times its initial weight. This was also valid for 
Table 7. Identification of protective clothing used by pesticide users.

\begin{tabular}{ccccc}
\hline Sample & Burning Testing & Solubility Testing & decision & Safety adequacy \\
\hline Jean & Cotton fiber & Cotton fiber & Confirmed & poor \\
Acrylic sweater & Blended cotton fiber & Blended cotton fiber & Confirmed & poor \\
Lacoste t-shirt & wool & wool & Confirmed & poor \\
Simple trousers & polyester & polyester & Confirmed & poor \\
Track suit & polyethylene & polyethylene & Confirmed & poor \\
Laminated fabric & Tri-acetate & Tri-acetate & Confirmed & poor \\
\hline
\end{tabular}

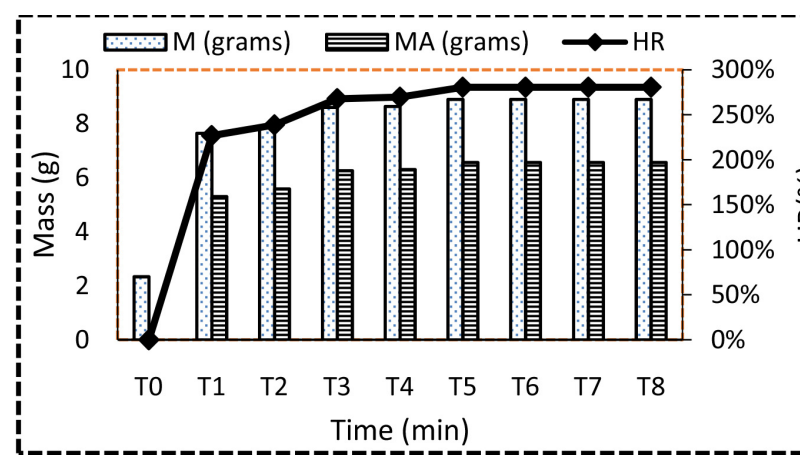

(a) Polyester

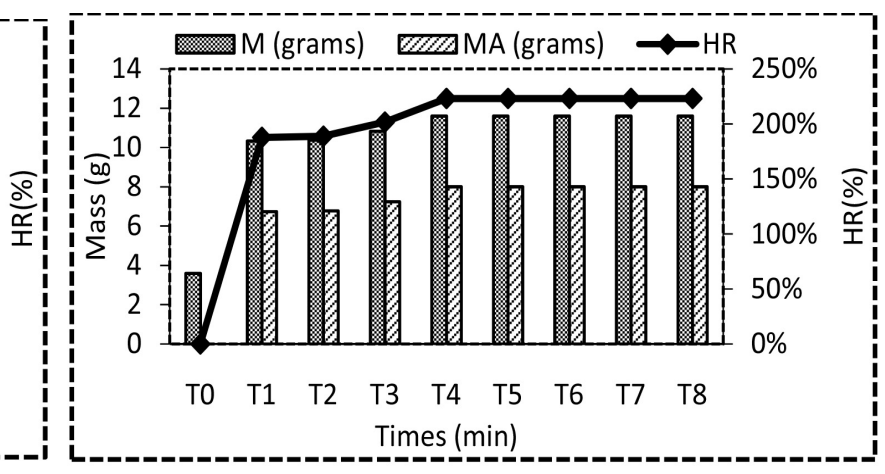

(b) Cotton/jean

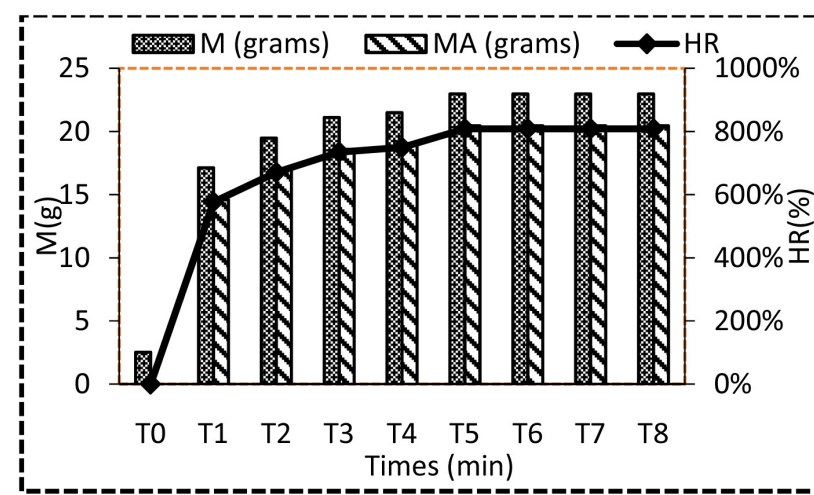

(c) Sweater

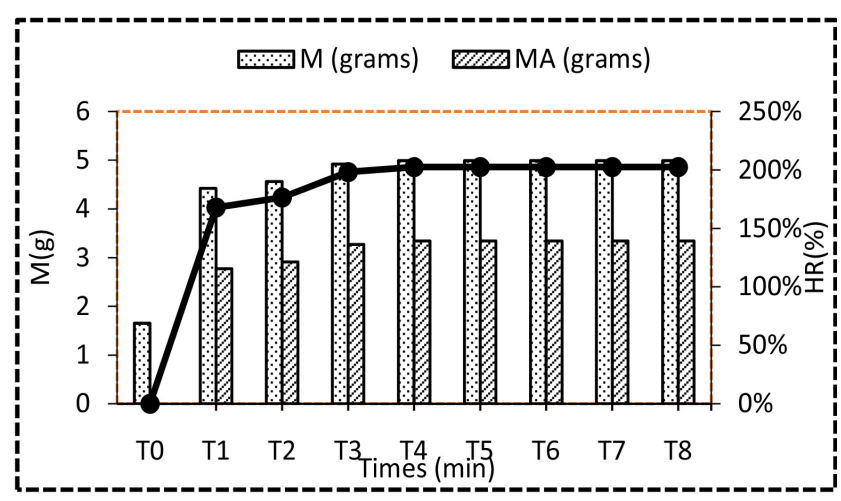

(d) Polyester

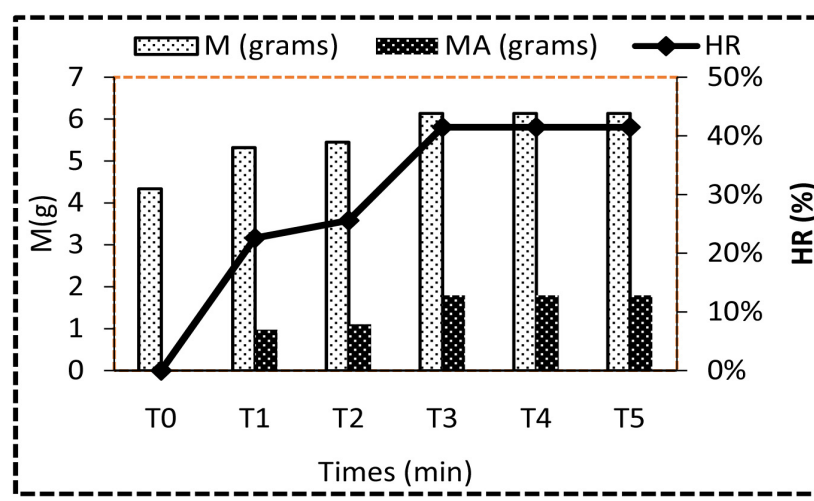

(e) Tri-acetate laminated fabric

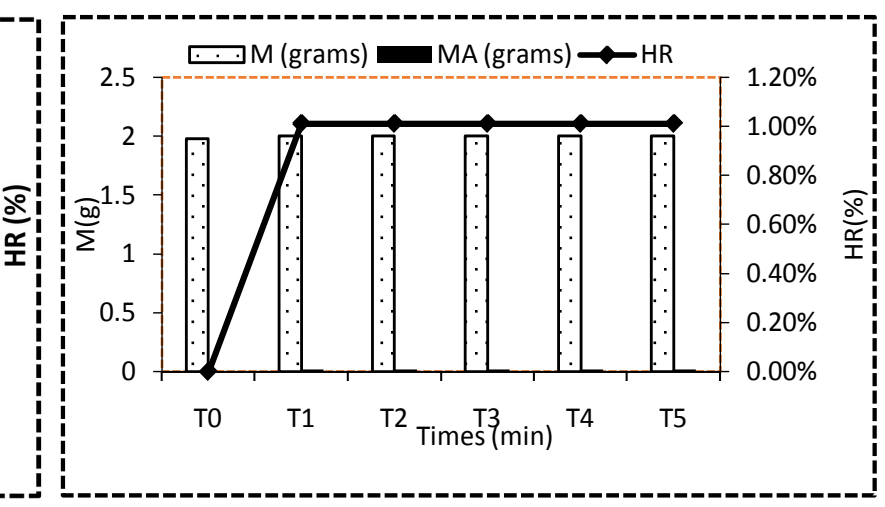

(f) Polyethylene laminated

Figure 2. Water absorbency of specimens. 
polyester: Figure 2(a) and Figure 2(d) (which have shown absorption of more than $200 \%$ of their normal weight). However, Figure 2(e) and Figure 2(f), which stand for Polyethylene Laminated and tri-Acetate Laminated fabrics and all had low absorption rate of water (varying from $1 \%$ to $40 \%$ respectively). But the second is very adequate for repelling any aqueous solutions.

It can be observed from this test that the specimen collected from the farmers although their clothing had different absorption capacities, none of them had the appropriate properties necessary to guarantee their safety when spraying. Even the jean material which has low rate of absorption is not able to retain water on its surface. However only samples 5 and 6 showed their high capacity to resistance to water and vapor, but sample 5 which is tri-acetic is a rigid material that does not allow free movement of the one who wears it. As for laminated polyethylene it is recommended for a better protection of the farmers because it gives assurance of complete protection without fear of contact with the pesticide liquid.

\subsubsection{Vapor Absorbency}

The vapor absorbency measured for all the specimens showed variation. Figure 3 presents various absorbencies. Given that the adult body temperature is $37 \mathrm{de}-$ grees Celsius, liquid coming into contact with the human body will not stay in liquid form due to the body temperature.

This graphic Figure 3 represents all the test of vapor absorption operated on different samples as track suit M, jeans M, WSM M, ALM M and PY M. The graphic shows that:

The Vapor absorption test on all the samples produced outstanding absorption the results for $\mathrm{S} 1$, had a dry mass of $3.59 \mathrm{~g}$ and 3.91 as final mass upon absorption thereby making a total of $0.32 \mathrm{~g}$ as absorbed mass; S2 had an initial mass of $2.53 \mathrm{~g}$ and a final mass of $6.81 \mathrm{~g}$ as final mass upon absorption, S3 with a dry mass of $2.63 \mathrm{~g}$ and a final mass of $3.88 \mathrm{~g}$ having a total of 1.25 grams absorbed.

S4, S5 had $1.65 \mathrm{~g}$ and $2.34 \mathrm{~g}$ respectively as initial mass and a final mass of 2.01 $\mathrm{g}$ and $2.60 \mathrm{~g}$ respectively. The samples had minute absorbed masses compared to $\mathrm{S} 2$ with a total $0.36 \mathrm{~g}$ and $0.12 \mathrm{~g}$ for S4 and S5 respectively.

\subsubsection{Permeability Testing}

Permeability of tested samples led to the obtaining of specific results which are shown in Figure 4.

The above Figure shows the permeation of test samples with S1 using 64 seconds to allow $50 \mathrm{~mL}$ of water poured on a fabric of $20 \mathrm{Cm}$ square to pass through the fabric, 06 seconds were used to allow $50 \mathrm{~mL}$ of water to pass through the textile giving a total permeation percentage of $90 \%$. For sample, 5, 8 seconds were used in order to allow $50 \mathrm{~mL}$ of water to pass through the fabric thereby allowing $47 \mathrm{~mL}$ and regaining $3 \mathrm{~mL}$ and having a total permeation percentage of $94 \%$. S4 used 21 seconds to allow $48 \mathrm{~mL}$ of water to pass through and 


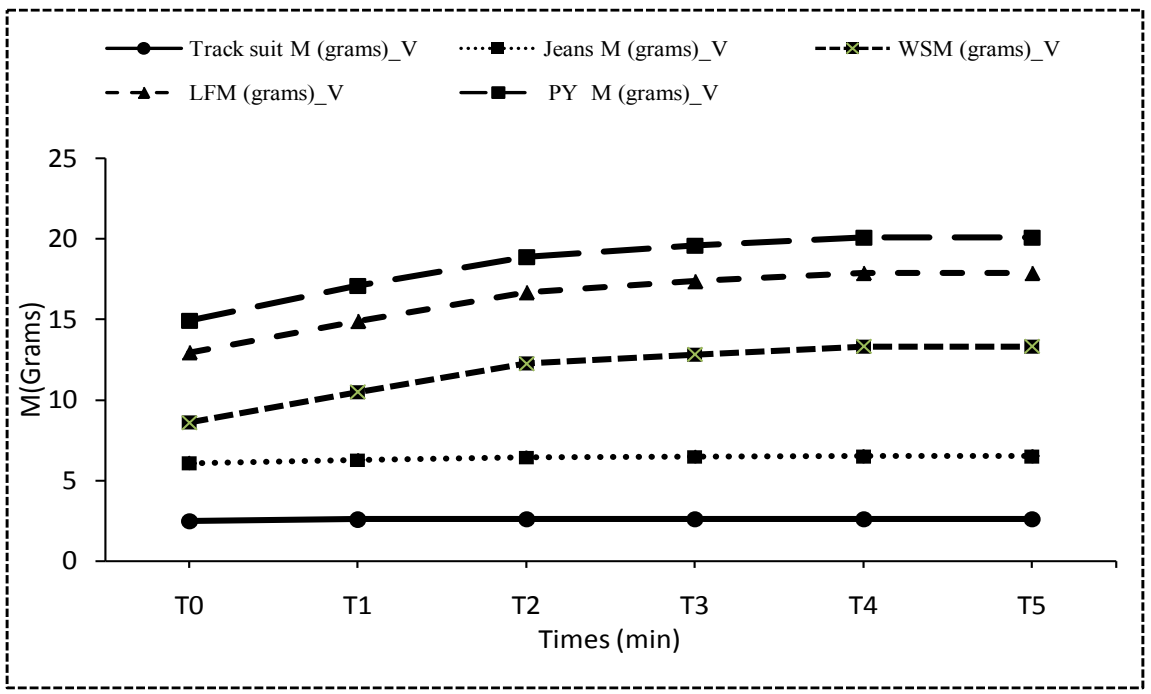

Figure 3. Vapor absorbency of all specimens.

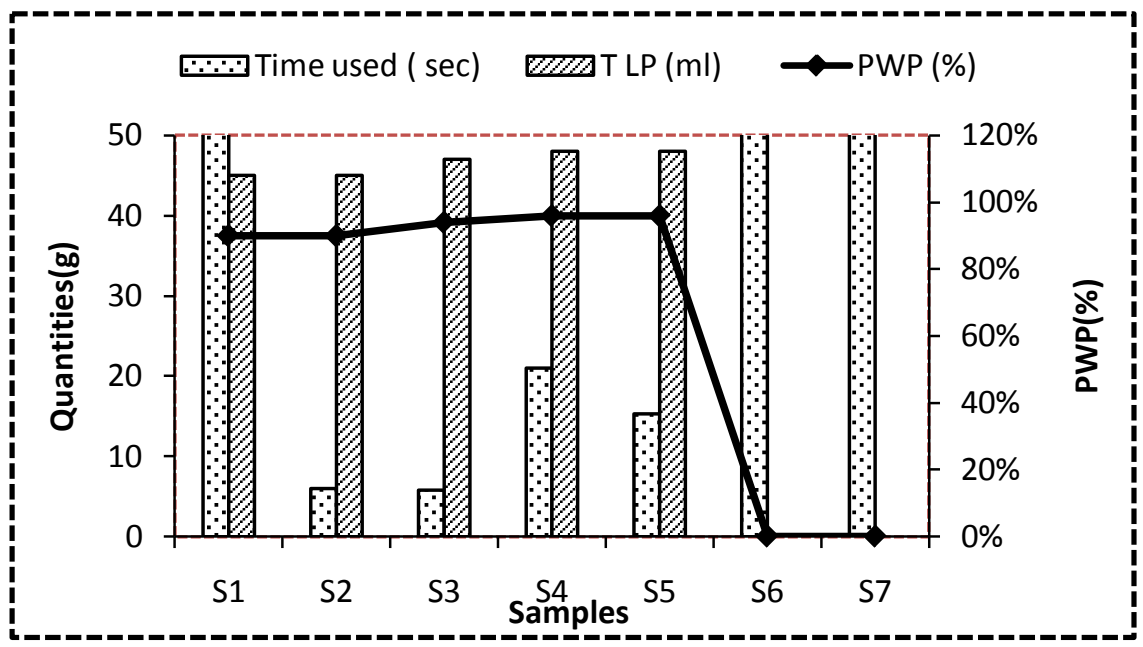

Figure 4. Permeability of all the specimens. Note: The time here, because of scale convenience was divided into 20 . Therefore have the real time; the time presented in this figure should be multiplied by 20 . Legend: $\mathrm{S} 1=$ cotton $1, \mathrm{~S} 2=$ wool, $\mathrm{S} 3=$ cotton, $\mathrm{S} 4=$ polyester, S5 = polyethylene, $\mathrm{S} 6=$ triacetate fabric, $\mathrm{S} 7=$ Polyethylene, $\mathrm{SEC}=$ Seconds, TLP = total liquid permeated, PWP = percentage of water permeated.

regained $2 \mathrm{~mL}$ with a total percentage of $96 \%$. For sample 5 (S5) 15.3 seconds was applied to allow $48 \mathrm{~mL}$ of water to pass through and regaining $2 \mathrm{~mL}$ with a total percentage of $96 \%$.

Sample 6 and Sample 7 (S6 and S7) which are recommended fabrics by researchers allowed $0.0 \mathrm{~mL}$ of water to pass through the fabric after 900 seconds (15 minutes) with a total percentage of $0.0 \%$. It can be seen from this test that, all the samples collected during the research (investigation) have been found to be all permeable at an elevated degree because they allowed $50 \mathrm{~mL}$ of water to pass through them in less than 20 seconds for most of them. Consequently, they expose the farmer to the effect of pesticides. Also, this test explains the reason why 
the majority of farmers are affected by various skin problems. However, it is necessary to appreciate the resistance of penetration of water of the two proposed materials for which in 90 seconds allowed no water to pass through.

Considering this weakness that exposes farmers to chemicals effects and that may cause them to fall sick at any moment of their life; and regarding their claim of not wearing protective clothing because it is expensiveness; an identification of an adapted local material was done.

\section{Discussion}

Statistically, farmers have similar demographic data according to experience, longevity, level of education and sex, in all the four villages. This similarity will lead to the same spraying practices because of their common background. Tarla et al. and Sonchieu et al. [4]-[9] have reported similar information in the same areas but in different villages. This common knowledge will obviously lead to the least variation of amount of pesticide residues in various foods produced in the very area [14]. The high number of years of experience can be an indicator of either high or low exposure of the consumer because the spraying factors could have been the same during that long period in cropping activity.

Personal Protective Equipment is intended to protect users from risks that cannot be eliminated by other more effective means. The poor use of PPE by farmers has been reported by Pouokam et al. [10]. No safety glasses, safety goggles, face shield, mask air-purifying neither respiratory, nor adapted clothing was reported. Hence, pesticide sprayers of this area are exposed to direct intoxication during their activity. Liver failure, alteration of entry routes (skin, respiratory tract and eyes) have been so far reported in neighboring villages with similar agricultural practices by Sonchieu et al. [4]. The hygienic variation of body care challenge after spraying generally affects the heath of operators: the more the bathing period extends the longer the contact time and the more toxicants penetrate the body [1]. Pesticides enumerated by Sonchieu et al. (2018) [8] are also used here and are mostly involved in symptoms and signs mentioned in the study which is on the same line with the study carried-out by Mejía et al. [15]. They have effects of various routes of penetrations such as eyes (irritation, watering, etc.), skin (irritation, burning, etc.), mouth, nostrils by inhalation. Ayaz et al. [16] reported that the entry of such toxicants will reduce the level of hemoglobin among pesticide sprayers and naturally will affect the oxygen transportation, responsible for breathing difficulties observed. Since they do not use adequate protective materials, the skin will be in contact with the chemical inducing contact effect known as cutaneous melanoma and biochemical transformations can be observed [17]. This is mostly caused by dithiocarbamates group (maneb, mancozeb and zineb) [16]. The lack of personal protective equipment can also be attributed to lack of financial means as mentioned by Zephania [18] while it is highly recommended by experts. Abang et al. [19] have reported this failure as a real common issue among Cameroonian farmers. 
The appropriate PPE will preserve users from intoxications. This study revealed the poor quality of clothes sprayers wear. There are normal clothes which are designed for comfortability and are not adapted to retain chemicals that penetrate the body [20] [21]. Their main protective characteristics such as permeability and absorbency towards protection from chemicals were shown to be very poor [21]. This is because they have strong hydrophilic groups (HNCOO) and hydrophilic segments leading to very high water absorption. A comparative laminated fabric chosen from local market shows better characteristics [22]. The water and vapor absorption of the said laminated fabric is low because of the shell fabric and lining as shown Bin et al. and Buzuayehu et al. [23] [24]. The Moisture Management Capacity (OMMC) index that indicates the capacity of fabrics to manage and transfer liquid was not measured but according to research conducted by Marolleau et al. and Hassan et al. [25] [26] [27], this index will be poor.

\section{Conclusion}

This study that was intended to bring out the safety of pesticide users shows that farmers are really exposed. The protective clothes they wear are very permeable and have high water and vapor absorbency inducing long term exposure or contact factor. However, a locally laminated cloth was identified with good characteristics (poor water and vapor absorption; low permeability) and can be analyzed for comfortability and propagation among farmers. The safety measures are poor and farmers manifested some signs and symptoms confirming their exposure to pesticides. This is one of many data showing the health risks among the same population. The local and national authorities may seek cheap and comfortable personal protective materials to extend the life span of these producers.

\section{Acknowledgements}

The authors sincerely thank the farmers who deliberately gave specimens for this study and all facilities offered by all the respondents met during the survey to achieve this work.

\section{Conflicts of Interest}

The authors declare no conflicts of interest regarding the publication of this paper.

\section{References}

[1] Atabila, A., Dung, T.P., Jonathan, N.H., Ross, S., Des, C. and Cordia, C. (2018) Health Risk Assessment of Dermal Exposure to Chlorpyrifos among Applicators on Rice Farms in Ghana. Chemosphere, 203, 83-89. https://doi.org/10.1016/j.chemosphere.2018.03.121

[2] Mejía, R., Edgar, Q., Alejandro, L., Alexandre, R., Humberto, C., Carlos, M.O., 
Eliette, V. and Dina, L.L. (2014) Pesticide-Handling Practices in Agriculture in El Salvador: An Example from 42 Patient Farmers with Chronic Kidney Disease in the BajoLempa Region. Occupational Diseases and Environmental Medicine, 2, 56-70. https://doi.org/10.4236/odem.2014.23007

[3] Sonchieu, J., Ngassoum, M.B., Nantia, A.E. and Laxman, P.S. (2017) Pesticides Applications on Some Vegetables Cultivated and Health Implications in Santa, North West-Cameroon. International Journal of Agriculture \& Environmental Science, 4, 39-46. https://doi.org/10.14445/23942568/IJAES-V4I2P108

[4] Sonchieu, J., Akono, E.N., Ngwamitang, C.T. and Ngassoum, B.M. (2018) Health Risk amongst Pesticides Sellers in Bamenda (Cameroon) and Peripheral Areas. Environmental Science and Pollution Research, 25, 9454-9460. https://doi.org/10.1007/s11356-018-1243-8

[5] Muhammad, A.B., Shafi, M.N., Syed, T.H.S. and Muhammad, I.B. (2012) Adsorption and Leaching Potential of Imidacloprid Pesticide through Alluvial Soil. American Journal of Analytical Chemistry, 3, 604-611. https://doi.org/10.4236/ajac.2012.38079

[6] Pinheiro, F.A. and Adissi, P.J. (2014) Pesticides Exposure: The Case of Workers on Growing Grapes in San Francisco Valley, Petrolina/Brazil. Agricultural Sciences, 5, 805-812. https://doi.org/10.4236/as.2014.510085

[7] Plan National de Développement et Planification (PNDP) (2015) Santa Council: Council Development Plan-CDP. MINPLADT, Yaoundé, 167 p.

[8] Yasser, E. (2017) Risk Factors among Greenhouse Farmers in Gaza Strip. Occupational Diseases and Environmental Medicine, 5, 1-10. https://doi.org/10.4236/odem.2017.51001

[9] Tarla, D.N., Manu, I.N., Tamedjouong, Z.T., Kamga, A. and Fontem, D.A. (2015) Plight of Pesticide Applicators in Cameroon: Case of Tomato (Lycopersicon esculentum Mill.) Farmers in Foumbot. Journal of Agriculture and Environmental Sciences, 4, 87-98.

http://jaesnet.com/journals/jaes/Vol_4_No_2_December_2015/10.pdf

[10] Pouokam, G.B., William, L.A., Alice, S.N. and Mohamed, E.S. (2017) A Pilot Study in Cameroon to Understand Safe Uses of Pesticides in Agriculture, Risk Factors for Farmers' Exposure and Management of Accidental Cases. Toxics, 5, 30. https://doi.org/10.3390/toxics5040030

[11] Medardo, A.V., Eduardo, M., Agustina, E., Flavia, S.D. and Bryan, M. (2017) Association between Cancer and Environmental Exposure to Glyphosate. International Journal of Clinical Medicine, 8, 73-85. https://doi.org/10.4236/ijcm.2017.82007

[12] Kimengsi, J.N. and Muluh, N.G. (2013) A Comparative Assessment of the Effect of Climatic Variations on the Crops of the Cameroon Development Corporation (CDC): Adaptation Options. Environment and Natural Resources Research, 3, 144-156. https://doi.org/10.5539/enrr.v3n1p144

[13] EN ISO 15025 Standard (2017) Protective Clothing-Protection against Heat and Flame-Method of Test for Limited Flame Spread. https://www.iso.org/standard/61739.html

[14] Jhalendra, P., Rijal, R.R., Rajan, G., Krishna, D.P., Sudan, G. and Sujata, P. (2018) Farmers' Knowledge on Pesticide Safety and Pest Management Practices: A Case Study of Vegetable Growers in Chitwan, Nepal. Agriculture, 8, 16. https://doi.org/10.3390/agriculture8010016

[15] Mohamed, H.S. (2012) Residues of Dimethoate and Profenofos in Tomato and Cu- 
cumber, and Dissipation during the Removal within Home Processing Method JKAU: The Meteorology. Environment and Arid Land Agriculture Science, 23, 51-63. https://doi.org/10.4197/met

[16] Ayaz, A., Majid, K., Shah, A. and Saleem, U.R. (2013) Occupational Exposure to Pesticides and Its Effects on Health Status of Workers in Swat, Khyber Pakhtunkhwa, Pakistan. Journal of Biology and Life Science, 4, 57-76. https://doi.org/10.5296/jbls.v4i2.3144

[17] Sobia, K., Rubina, M., Rehana, M., Masarrat, Y., Muhammad, A., Fozia, T. and Rabiya, F. (2013) Monitoring of Biochemical Effects of Organochlorine Pesticides on Human Health. Health, 5, 1342-1350. https://doi.org/10.4236/health.2013.58182

[18] Zephania, N.F. (2014) Montane Resources Exploitation and the Emergence of Gender Issues in Santa Economy of the Western Bamboutos Highlands, Cameroon. International Journal of Geography and Regional Planning Research, 1, 1-12.

[19] Abang, A.F., Kouame, C.M., Abang, M., Hannah, R. and Fotso, A.K. (2013) Vegetable Growers Perception of Pesticide Use Practices, Cost, and Health Effects in the Tropical Region of Cameroon. International Journal of Agronomy and Plant Production, 4, 873-883.

[20] Mourad, K. and Sara, S.S. (2016) Cotton Utilization in Conventional and NonConventional Textiles-A Statistical Review. Agricultural Sciences, 7, 747-758. https://doi.org/10.4236/as.2016.710069

[21] Abdeen, Z. and Mohammad, S.G. (2014) Study of the Adsorption Efficiency of an Eco-Friendly Carbohydrate Polymer for Contaminated Aqueous Solution by Organophosphorus Pesticide. Open Journal of Organic Polymer Materials, 4, 16-28. https://doi.org/10.4236/ojopm.2014.41004

[22] Gupta, A.K. (1997) Characterization of Polymers and Fibres. In: Gupta, V.B. and Kothari, V.K., Eds., Manufactured Fibre Technology, Chapter 10, Chapman \& Hall, London, 203-247. https://doi.org/10.1007/978-94-011-5854-1

[23] Li, C., et al. (2017) Waterproof and Moisture Permeability Performance of Laminated Fabrics with Electrospunnano Fibrous Membrane. Journal of Textile Engineering and Fashion Technology, 2, 363-368. https://doi.org/10.15406/jteft.2017.02.00057

[24] Buzuayehu, A., Ananda, M.H.C. and Enyew, A. (2018) Summary on Adsorption and Photocatalysis for Pollutant Remediation: Mini Review. Journal of Encapsulation and Adsorption Sciences, 8, 225-255. https://doi.org/10.4236/jeas.2018.84012

[25] Marolleau, A., Salaün, F., Dupont, D., Gidik, H. and Ducept, S. (2017) Influence of Textile Physical Properties and Thermo-Hydric Behaviour on Comfort. Journal of Ergonomics, 7, 223. https://doi.org/10.4172/2165-7556.1000223

[26] Hassan, T.G. and Abolfazl, H. (2016) Investigating the Relationship between Porosity and Permeability Coefficient for Pervious Concrete Pavement by Statistical Modelling. Materials Sciences and Applications, 7, 101-107. https://doi.org/10.4236/msa.2016.72010

[27] Sen, K. (2000) Textile Fibres: Classification and Identification. In: Kothari, V.K., Ed., Quality Control, Chapter 4, Textile Dept. IIT, New Delhi, 46-54. 